\title{
Sağlık Bilimleri Fakültesi Öğrencilerinin Siberkondri Düzeyleri ve İlişkili Faktörlerin İncelenmesi
}

\author{
DOI: $10.26466 /$ opus.616396
}

*

\section{Handan Ertaş* - Ramazan Kıraç}

* Doç. Dr, Selçuk Üniversitesi, Sağlık Bilimleri Fakültesi, Selçuklu / Konya / Türkiye

E-Posta: handanertas@selcuk.edu.tr

ORCID: 0000-0003-1794-0296

** Arş.Gör.Dr.,Kahramanmaraş Sütçü İmam Üniversitesi,İiBF,Onikişubat/Kahramanmaraş/Türkiye

E-Posta: ramazan46k@gmail.com

ORCID: $\underline{0000-0002-8032-1116}$

*** Y. L. Öğrencisi, Selçuk Üniversitesi, Sağlık Bilimleri Fakültesi, Selçuklu / Konya/ Türkiye

E-Posta: snurunal1@gmail.com _ORCID: 0000-0002-0526-1651

\section{Öz}

Son yillarda teknolojinin gelişmesi ile birlikte bireyler bilgiye çoğunlukla dijital ortamlardan erişmektedirler. Sanal ortamlardan bilgiye erişmek daha hızh olduğu için, kişiler sağllkla ilgili bilgiye erişmekte bu yolu tercih etmektedirler. Fakat bu ortamlarda çok fazla bilgi kirliliği olduğu için, bireyler doğru bilgiye ulaşmakta zorlanmakta veya eriştikleri bilgi bireyde kaygı düzeyini artırmaktadır. Bu araştırmada Sağlık Bilimleri Fakültesi öğrencilerinin siberkondri düzeyleri ve ilişkili faktörlerin incelenmesi amaçlanmaktadır. Araştırmanın örneklemini Selçuk Üniversitesi Sağllk Bilimleri Fakültesinde öğrenim gören 450 öğrenci oluşturmaktadır. Araştırmada Batıgün ve ark. (2018) tarafindan geliştirilen 28 maddelik Siberkondri Ölçeği kullanılmıştır.Araştırmaya katılanlarm \%54,3'ü kadın, \%25,5'i Sağglı Yönetimi, \%14,4'ü Beslenme ve Diyetetik bölümünde öğrenim görmektedir. Öğrencilerin \%49,2'si 4-6,\%19'u 7-9 saat internette günlük zaman geçirdiğini ve $\% 67,7$ 'si internette yer alan bilgilere güvenmediğini belirtmiştir. Son bir yıl içinde doktora başvuru sayılarına bakuldığında öğrencilerin \%47,7'si 6-10, \%19,7'si 11-15 defa doktora başvuru yaptı̆̆ıı belirtmiştir. Araştırma sonucuna göre kadınların ve sürekli ilaç kullanımına sahip öğrencilerin siberkondri düzeylerinin daha yüksek olduğu sonucuna varılmıştır.Çalışma sonucunda bireylerin algılanan să̆glık durumları iyiye gittikçe siberkondri düzeyinin düşeceği tespit edilmiştir.

Anahtar Kelimeler: Siberkondri, Çevrimiçi, Sağlık Bilgisi, Sağlık Kaygısı 


\title{
Study Of Cybercondria Levels And Related Factors Of Faculty Of Health Sciences Students
}

\begin{abstract}
In recent years with the development of technolog, individuals access information mostly from digital media. Since it is faster to access information from digital environments, people prefer this way to access information about health. However, since there is a lot of information pollution in these environments, individuals have difficulty in reaching the correct information or the information they access increases the level of anxiety in the individual. The aim of this study is to investigate the cyberchondria levels and related factors of the students of the Faculty of Health Sciences. The sample of the study consists of 450 students studying at the Faculty of Health Sciences of Selçuk University. In the study Batıgun et. al. (2018) was used by the 28-item Cyberchondria Scale. 54.3\% of the participants were female, $25.5 \%$ were in Health Management and $14.4 \%$ were in Nutrition and Dietetics. $49.2 \%$ of the students spend 4-6 hours, 19\% 7-9 hours on the internet and $67.7 \%$ do not trust the information on the internet. Looking at the number of doctorate applications in the last year, $47.7 \%$ of the students stated that they have applied for doctorate 6-10 times, and 19.7\% stated that they have applied for doctorate 11-15 times. According to the results of the study, it was concluded that cyberchondria levels of women and students with continuous drug use were higher. As a result of the study, it was found that as the perceived health status of individuals improved, the cyberchondria level would decrease.
\end{abstract}

Keywords: Cyberchondria, Online Health Information, Health Anxiety 


\section{Giriş}

Dijital teknolojinin artan etkisi ile birlikte daha fazla insan interneti tıbbi bilgi aramak için birincil kaynak olarak kullanmaktadır (Mathes et all., 2018, s.204). Türkiye İstatistik Kurumu'nun "2015 Hane halkı Bilişim Teknolojileri Kullanım Araştırması"na göre Türkiye'de internet kullanım oranı \%55,9'dur (TUIK, 2015). Aynı araştırmada internet kullanan bireylerin \%66,3'ünün sağlıkla ilgili konularda araştırma yaptıklarını ve bu kullanıcıların $\% 75,2$ sinin kadın olduğu sonucuna varılmıştır (TUIK, 2015). ABD' de yapılan bir ankette yetişkin nüfusun \%80'ninin sağlık bilgilerine erişim için interneti kullandığ sonucuna varılmıştır (Pew Internet American Life Project, 2012). Sağlık içerikli web sitelere olan ilgi de gün geçtikçe artmaktadır. Sağlık bilgilerine erişim için internetin oldukça popüler hale gelmesinde, internetin ucuz, anonim ve hızlı bir araç olması etkili olabilir (McElroy ve Sheylin, 2014, s.259).

Çevrimiçi sağlık bilgisi araması davranışı sağlıklı beslenme alışkanlıkları edinme, ilaç tedavilerine uyum sağlama, düzenli egzersiz yapma, etkili sağlık kararları alabilme gibi olumlu ve koruyucu davranışlar sağlayabileceği gibi, uzman olmayan kişiler tanı koyma amacıyla kullanıldığında problem yaratabilmektedir (Aiken et all., 2012, s.72: Huberty et all., 2013, s.1364: Lemire ve Sicotte, 2008, s.137). İnternet, kullanıcilara geniş bir bilgi kaynağı sunarken; kişilerin yaş, cinsiyet, yaşam tarzı gibi bireysel etmenleri göz önünde bulunduramadığından kaba bir tanı yöntemidir (White ve Horvitz, 2009, s.32). İnternet kullanıcılara zamanla daha geniş bir bilgiye erişim imkânı sunsa da bu bilgilerin kalitesinde herhangi bir gelişme yaşanmamıştır ve çok az sayıda internet kullanıcısı kaynakların güvenilirliğini kontrol etmektedir(Benigeri ve Pluye, 2003, s.382: Powell et all., 2003, s.75). Bireylere bilgiye ulaşım açısından maliyet etkinliği, anonimlik, sosyal destek, geniş bilgi kaynağının olması gibi pek çok avantaj sağlıyor olsa da kullanıcıların doğruluğu kanıtlanmamış, çelişkili veya eski bilgilere maruz kalması gibi olumsuzluklara da sahiptir (Muse et all., 2012, s.191; Rains, 2007, s.668). Bu olumsuzlukların en önemlilerinden biri de bu bilgileri okuyan bireylerin sağlık anksiyetelerinin artmasıdır (Fergus, 2014, s.506; Baumgartner ve Hartmann, 2011, s.614). White ve Horvitz (2009)' in yapmış oldukları çalışmada internette sağlık bilgisi arayan kişilerin \%38'inin sağlık kaygısında artış olduğu tespit edilmiştir.

Sağlık kaygısı, bireylerin vücutlarında gelişen herhangi bir duyumu yanlış yorumlayarak sağlıkları hakkında büyük bir endişe duyma durumu iken; 
siberkondri sağlık konulu yapılan çevrimiçi aramalar sonucu bireylerin sağlık kaygılarında görülen ciddi artış olarak tanımlanmaktadır (Asmundson ve Taylor, 2005, s.3; Muse et all., 2012, s.190). Starcevic ve Berle (2013) siberkondriyayı, sağlıkla ilgili gerçekleşen anksiyeteyi azaltmak amacıyla yapılan uzun süreli ve yoğun internet kullanımı olarak tanımlamaktadır. Yüksek sağlık kaygısı sadece hastanın ve çevresinin sıkıntısı ile sınırlı kalmaz aynı zamanda yüksek tıbbi bakım kullanımını da beraberinde getirir (Barsky, Ettner, Horsky ve Bates, 2001).

Siberkondriyaklar, arama motorları vasitasıyla kolaylıkla filtresiz sağlık bilgilerine ulaşmaktadırlar. Yapılan çalışmalarda sağlıkla ilgili sitelerde yer alan bilgilerin kalitesi ve doğruluğunun şüpheli olduğu sonucuna varılmıştır (Kunst, Groot, Latthe, Khan, 2002; Rajani, Mukherjee, Chambers, Murmurs, 2007). Bu nedenle sağlıkla ilgili bilgi edinmek için internetin kullanılması bireylerin çelişkili, yanlış veya güncel olmayan bilgilere maruz kalma riskini arttırabilir. White ve Horvitz (2009) çalışmalarında, arama motorlarınının çeşitli semptomlara göre arama yapan kullanıcıları daha ciddi ve olumsuz etkiye sebep olacak sayfalara yönlendirildikleri ve bu ciddi sonuçların da bireylerin kaygilarını arttırarak derinlemesine araştırmalar yapmalarına sebep olmaktadır. Aynı çalışmada bu tür aramaların bireylerin günlük yaşamını olumsuz etkilediği sonucuna da ulaşılmıştır.Yapılan çalışmalar incelendiğinde siberkondri ve sağlık kaygısı arasında pozitif yönlü bir ilişki olduğu, sağlık anksiyete puanları yüksek olan kişilerin internette daha fazla zaman geçirdikleri ve bu kişilerin internet araması sonrası daha fazla endişe ve sıkıntı duydukları sonucuna ulaşılmıştır (Norr, Allan, Boffa, Raines, Schmidt, 2015; Barke, Bleichhardt, Rief, Doering, 2016;Norr, Albanese, Oglesby, Allan, Schmidt,2015; Baumgartner ve Hartmann, 2011).

Yapılan bazı çalışmalarda siberkondrinin sağlık hizmetleriyle ilişkisine de odaklanılmaktadır. Fergus (2014) anksiyeteye sebep olan siberkondrinin sağlık hizmeti kullanımını da arttıracağı dile getirmiştir. Fox (2015)'un çalışmasında çevrimiçi sağlık bilgisi arayan bireylerin \%46'sı edindikleri bilgi doğrultusunda sağlık personeline danısma ihtiyacı hissetmektedir. Berezovska ve ark. (2010) çalışmasında ise çevrimiçi sağlıkla ilgili arama yapan kişilerin \%30'unun sağlık hizmeti kullandığ1 sonucuna varılmıştır. Ravdin ve Guide (2008) ve Keller, Paradala, Petty (2008) ise siberkondrinin doktorhasta iletişiminde olumsuzluklara sebep olabileceğini vurgulamaktadır. Bu 
ise kişiye fazladan sağlık harcamasına (ör: doktor doktor gezme) sebep olacaktır. Bu bağlamda gerek sebep olduğu sağlık problemleri gerek sebep olabileceği maliyetler düşünüldüğünde siberkondrinin daha iyi anlaşılması gerekmektedir. Ayrıca bu durumu kavramak ve olumsuzlukların en aza indirmek için stratejilerin belirlenmesi önemlidir. Bu stratejilerin belirlenmesinde sağlık yöneticileri, psikologlar, halk sağlığı ve bilgi teknolojisi uzmanları iş birliği içinde çalışmalıdır.Bu bağlamda mezun olduklarında mesleklerini profesyonel olarak icra etmeye başlayacak öğrenciler için siberkondrinin bilinmesi oldukça önem arz etmektedir. Bu çalışmada ise Sağlık Bilimleri Fakültesi öğrencilerinin siberkondri düzeyleri ve ilişkili faktörlerin incelenmesi amaçlanmaktadır. Konuyla ilgili yapılan çalışmalar sınırlı sayıda olduğundan yapılan çalışma literatüre destek sağlayacağı düşünülmektedir.

\section{Yöntem}

Araştırmada nicel araştırma deseni ve kolayda örnekleme yöntemi kullanılmıştır. Araştırmanın evrenini Selçuk Üniversitesi Sağlık Bilimleri Fakültesi'nde hemşirelik, sosyal hizmet, çocuk gelişimi, beslenme ve diyetetik ve sağlık yönetimi bölümlerinde öğrenim gören toplam 1.844 öğrenci oluşturmaktadır. Araştırmada örneklem büyüklüğünün belirlenebilmesi için Yazıc1oğlu ve Erdoğan (2004) tarafından oluşturulan belirli evrenler için kabul edilebilir örneklem büyüklükleri tablosundan yararlanılmış ve 2500 kişilik evrene karşılık 333 kişilik örneklem büyüklügünün yeterli olduğu görülmüş ve 451 kişi çalışma kapsamına dâhil edilmiştir.Veriler elektronik ortamda toplanmıştır. Anket formu internet ortamında hazırlanan bir link aracilığı ile bölümlerin varolan Watsapp gruplarına gönderilmiştir. Böylece 750 kişiye ulaşılmış ve geri dönüş yapanların sayısı 451 olarak ortaya çıkmıştır. Araştırmada kullanılan anket 2 bölümden oluşmaktadır. İlk bölümde demografik bilgilerin öğrenilmesi amaçlanmış ve bu bağlamda yaş, cinsiyet, kronik hastalık durumu gibi 9 soru yer almıştır. İkinci bölümde ise Durak Batıgün ve ark. (2018) tarafından geliştirilen 28 maddellik Siberkonri Ölçeği'nin soruları yer almıştır. Ölçek beş alt boyuttan oluşmaktadır bunlar; doktor-hasta etkileşimi, işlevsel olmayan internet kullanımı, kaygıyı artıran faktörler, kompulsiyon/hipokondri, kaygıyı azaltan faktörlerdir. Siberkondri ile ilgili sorular "1=Kesinlikle katılmıyorum ve 5=Kesinlikle katılıyorum" şeklindeki 5'li likert tipindeki ölçekle, demografik sorular ise kapalı uçlu olarak sunulmuştur. 
Araştırmada ölçeğin Cronbach Alfa katsayısı 0,90 olarak bulunmuştur. Ankette elde edilen veriler SPSS versiyon21 programında analiz edilmiştir.

\section{Bulgular}

Araştırmaya katılan bireylere ait bulgular aşağıda tablolar şeklinde verilmiştir.

Tablo 1. Katılımcılara Ait Demografik Özellikler

\begin{tabular}{|c|c|c|c|}
\hline & & $\mathbf{F}$ & $\%$ \\
\hline \multirow{2}{*}{ Cinsiyet } & Erkek & 206 & 45,7 \\
\hline & Kadın & 245 & 54,3 \\
\hline \multirow{5}{*}{ Bölüm } & Beslenme ve Diyetetik & 65 & 14,4 \\
\hline & Çocuk Gelişimi & 74 & 16,4 \\
\hline & Hemşirelik & 98 & 21,7 \\
\hline & Sosyal Hizmet & 99 & 22 \\
\hline & Sağllk Yönetimi & 115 & 25,5 \\
\hline \multirow{3}{*}{ Yaş } & $18-20$ & 229 & 50,8 \\
\hline & $21-23$ & 210 & 46,6 \\
\hline & $24+$ & 12 & 2,6 \\
\hline Günlük & $1-3$ & 143 & 31,7 \\
\hline İnternette & $4-6$ & 222 & 49,2 \\
\hline Geçirilen Süre & $7-9$ & 86 & 19,1 \\
\hline \multirow{4}{*}{ Aylık Gelir } & $10001-2000 \mathrm{TL}$ & 115 & 25,5 \\
\hline & 2001-3000 TL & 123 & 27,2 \\
\hline & 3001-4000 TL & 99 & 22 \\
\hline & $4000+\mathrm{TL}$ & 114 & 25,3 \\
\hline Sürekli İlaç & Var & 121 & 26,8 \\
\hline Kullanımı & Yok & 330 & 73,2 \\
\hline \multirow{2}{*}{ Kronik Hastalık } & Var & 116 & 25,7 \\
\hline & Yok & 335 & 74,3 \\
\hline \multirow[t]{2}{*}{ İnternette yer alan Bilgilere güven } & Evet & 305 & 67,7 \\
\hline & Hayır & 146 & 32,3 \\
\hline Algilanan & Kötü/Çok kötü & 23 & 5,1 \\
\hline Sağlik & Orta & 87 & 19,3 \\
\hline \multirow[t]{2}{*}{ Durumu } & İyi & 130 & 28,8 \\
\hline & Çok İyi & 211 & 46,8 \\
\hline Son 1 Yll & $1-5$ & 147 & 32,6 \\
\hline İçinde Doktora & $6-10$ & 215 & 47,7 \\
\hline Başvuru & $11-15$ & 89 & 19,7 \\
\hline$\underline{S a y ı s 1}$ & & & \\
\hline
\end{tabular}


Tablo 1'e göre araştırmaya katılanların $\% 54,3$ 'ü kadın, \%50,8'si 18-20, \%2,6'sı 24+ yaş aralığındadır. Katılımcıların \%25,5'i Sağlık Yönetimi,\%22'si Sosyal Hizmet ve \%14,4'ü Beslenme ve Diyetetik bölümünde öğrenim görmektedir. Öğrencilerin \%49,2'si 4-6,\%19'u 7-9 saat internette günlük zaman geçirdiğini ve $\% 32,3$ 'ü internette yer alan bilgilere güvenmediğini belirtmiştir. Katılımciların \%27,3 ü 2001-3000 TL, \%22' si 30001-4000 TL arası aylık gelir durumuna sahiptir. Son bir yıl içinde doktora başvuru sayılarına bakıld1ğında öğrencilerin \%47,7'si 6-10, \%19,7'si 11-15 defa doktora başvuru yaptığını belirtmiştir. Katılımcıların \%25,7'si kronik hastalığa sahipken; \%26,8'inin sürekli ilaç kullanımı mevcuttur.

Tablo 2. Cinsiyet ile Siberkondri ve Ölçek Alt Boyut Ortalamalan Arasındaki Farklılı̆̆a Ait T Test

\begin{tabular}{lllllll}
\hline Cinsiyet & & $\mathbf{n}$ & Ort. & Sd & t & p \\
\hline Siberkondri & Erkek & 206 & 2,449 & 0,62457 & 3,935 & 0,000 \\
Ortalaması & Kadın & 245 & 2,675 & 0,59399 & & \\
\hline İslevsel Olmayan & Erkek & 206 & 2,675 & 0,75882 & $-3,480$ & 0,001 \\
İnternet Kullanımı & Kadın & 245 & 3,0265 & 0,77800 & & \\
\hline Doktor-Hasta & Erkek & 206 & 2,4068 &, 80665 & $-2,275$ & 0,009 \\
Etkileşimi & Kadın & 245 & 2,6147 &, 86807 & & \\
\hline Kaygiyı & Erkek & 206 & 2,5138 &, 88786 & $-2,275$ & 0,025 \\
Arttıran Faktörler & Kadın & 245 & 2,6898 &, 75516 & & \\
\hline Kaygıyı & Erkek & 206 & 2,6757 &, 76515 & $-1,043$ & 0,298 \\
Azaltan Faktörler & Kadın & 245 & 2,7478 &, 70050 & & \\
\hline Kompülsiyon & Erkek & 206 & 1,9061 &, 79894 & 5,249 & 0,000 \\
/Hipokondri & Kadın & 245 & 2,2993 &, 78463 & & \\
\hline
\end{tabular}

Tablo 2'de görüldüğü üzere araştırmaya dâhil olan kişilerin cinsiyeti ile siberkondri genel ortalaması ve ölçeğin alt boyut ortalamaları arasında t testi analizi yapılmıştır. Analiz sonuçlarına göre; genel siberkondri düzeyi, işlevsel olmayan internet kullanımı, doktor- hasta etkileşimi, kompülsiyon/ hipokondri ve kaygıyı arttıran faktörler ile cinsiyet arasında anlamlı bir fark bulunmuştur $(\mathrm{p}<0,05)$. Kadınların $(\bar{x}=2,67)$ siberkondri düzeyleri erkeklere $(\bar{x}=2,44)$ göre daha yüksek çıkmıştır. Ayrıca kadınların işlevsel olmayan internet kullanımlarının, doktor- hasta etkileşiminin, kaygiyı arttıran faktörlerin ve kompülsiyon/hipokondri durumlarının erkeklere oranla daha yüksek olduğu sonucuna ulaşılmıştır. 
Tablo 3. Sürekli İlaç Kullanımı ile Siberkondri ve Ölçeğin Alt Boyut Ortalamalar Arasındaki Farklılı̆̆a Ait T Testi

\begin{tabular}{|c|c|c|c|c|c|c|}
\hline \multicolumn{2}{|l|}{$\underline{\text { Sürekli İlaç Kullanımı }}$} & \multirow{2}{*}{$\frac{\mathbf{n}}{121}$} & \multirow{2}{*}{$\begin{array}{l}\text { Ort. } \\
2,6873\end{array}$} & \multirow{2}{*}{$\frac{\text { Sd }}{, 64328}$} & \multirow{2}{*}{$\frac{\mathbf{t}}{2,417}$} & \multirow{2}{*}{$\frac{\mathbf{p}}{0,016}$} \\
\hline Siberkondri & Var & & & & & \\
\hline Genel Ortalaması & Yok & 330 & 2,5293 & 60374 & & \\
\hline İşlevsel Olmayan & Var & 121 & 3,0661 & 81066 & 2,579 & 0,010 \\
\hline İnternet Kullanımı & Yok & 330 & 2,8540 & ,76005 & & \\
\hline Doktor-Hasta & Var & 121 & 2,8066 & 84496 & 4,451 & 0,000 \\
\hline Etkileşimi & Yok & 330 & 2,4145 & ,82294 & & \\
\hline Kaygıyı Arttıran & Var & 121 & 2,6474 & 81143 &, 594 & 0,553 \\
\hline Faktörler & Yok & 330 & 2,5955 & ,82691 & & \\
\hline Kaygıyı Azaltan & Var & 121 & 2,7074 & 67134 &,- 130 & 0,896 \\
\hline Faktörler & Yok & 330 & 2,7176 & ,75238 & & \\
\hline Kompülsiyon & Var & 121 & 2,2328 & ,85998 & 1,790 & 0,740 \\
\hline /Hipokondri & Yok & 330 & 2,0783 & 79418 & & \\
\hline
\end{tabular}

Tablo 3'te görüldügüü üzere araştırmaya dâhil olan kişilerin sürekli ilaç kullanımı ile siberkondri genel ortalaması ve ölçeğin alt boyut ortalamaları arasında t testi analizi yapılmıştır. Analiz sonuçlarına göre; siberkondrigenel düzeyi ile sürekli ilaç kullanımı arasında anlamlı bir fark bulunmuştur $(\mathrm{p}<0,05)$. Ayrıca ölçeğin alt boyutlarından olan doktor-hasta etkileşimi ve işlevsel olmayan internet kullanımı ile sürekli ilaç kullanımı arasında anlamlı bir fark bulunmuştur $(\mathrm{p}<0,05)$. Sürekli ilaç kullananların $(\bar{x}=2,68)$ siberkondri düzeyleri kullanmayanlara $(\bar{x}=2,52)$ göre daha yüksek çıkmıştır.Sürekli ilaç kullanan bireylerin işlevsel olmayan internet kullanımları ve doktor- hasta etkileşimleri, kullanmayanlara göre daha yüksek çıkmıştır.

Tablo 4'de görüldüğü üzere araştırmaya dâhil olan kişilerin kronik hastalığa sahip olma durumları ile siberkondri genel ortalaması ve ölçeğin alt boyut ortalamaları arasında t testi analizi yapılmıştır. Analiz sonuçlarına göre; işlevsel olmayan internet kullanımı ve doktor hasta etkileşimi alt boyutu ile kronik hastalığa sahip olma durumu arasında anlamlı bir fark bulunmuştur $(\mathrm{p}<0,05)$. Kronik hastalığa sahip olan bireylerin işlevsel olmayan internet kullanımları ve doktor- hasta etkileşimleri, kronik hastalığa sahip olmayanlara göre daha yüksek çıkmıştır. 
Tablo 4. Kronik Hastalığa Sahip Olma Durumu ile Siberkondri ve Ölçeğin Alt Boyut Ortalamalarn Arasındaki Farklılı̆̆a Ait T Testi

\begin{tabular}{|c|c|c|c|c|c|c|}
\hline Kronik Hastalık & & $\mathbf{n}$ & Ort. & Sd & $t$ & p \\
\hline Siberkondri & Var & 206 & 2,6573 & 66344 & 1,732 & 0,101 \\
\hline Genel Ortalaması & Yok & 245 & 2,5423 & ,59947 & & \\
\hline İşlevsel Olmayan & Var & 206 & 3,0761 & ,82632 & 2,669 & 0,008 \\
\hline İnternet Kullanımı & Yok & 245 & 2,8537 & ,75445 & & \\
\hline Doktor-Hasta & Var & 206 & 2,7121 & 85964 & 2,864 & 0,004 \\
\hline Etkileşimi & Yok & 245 & 2,4531 & 83224 & & \\
\hline Kaygiyı Arttıran & Var & 206 & 2,6221 & ,80648 & 0,193 & 0,847 \\
\hline Faktörler & Yok & 245 & 2,6050 & ,82873 & & \\
\hline Kaygıyı Azaltan & Var & 206 & 2,6793 & 65667 &,- 650 & 0,516 \\
\hline Faktörler & Yok & 245 & 2,7272 & ,75531 & & \\
\hline Kompülsiyon & Var & 206 & 2,2098 & ,83467 & 1,360 & 0,175 \\
\hline /Hipokondri & Yok & 245 & 2,0886 & ,80601 & & \\
\hline
\end{tabular}

Tablo 5'te görüldügü üzere araştırmaya dâhil olan kişilerin bölümleri ile siberkondri ortalaması ve ölçek alt boyutları arasında tek yönlü varyans testi yapılmıştır. Bölüm ile siberkondri düzeyleri, işlevsel olmayan internet kullanımı, doktor-hasta etkileşimi, Kompülsiyon/Hipokondri alt boyutları arasındaanlamlı bir fark bulunmuştur $(\mathrm{p}<0,05)$. Siberkondri ile bölüm arasında yapilan Post-Hoc (Games-Howell) testine göre: Çocuk gelişimi $\left(\mathrm{x}^{\overline{\mathrm{N}}=2,81)}\right.$ bölümü öğrencilerinin siberkondri düzeyleri hemşirelik $(\bar{x}=2,48)$, sosyal hizmet $(\bar{x}=2,54)$ ve sağllk yönetimi $(\bar{x}=2,40)$ bölümü öğrencilerine göre daha yüksek olduğu sonucuna ulaşılmıştır. Çocuk Gelişimi $\left(x^{\bar{x}}=3,09\right)$, bölümü öğrencilerinin işlevsel olmayan internet kullanımlarının hemşirelik $(\bar{x}=2,76)$, ve sağlik yönetimi $(\bar{x}=2,73)$ bölümü öğrencilerine nazaran daha yüksek olduğu görülmüştür. Bununla beraber çocuk gelişimi $(\bar{x}=2,61)$, bölümünde öğrenim gören öğrencilerin, sağlik yönetimi $(\bar{x}=3,09)$, , sosyal hizmet $(\bar{x}=2,03)$, ve hemşirelik $(\bar{x}=1,98)$ bölümü öğrencilerine oranla hipokondri düzeylerinin daha yüksek olduğu görülmüştür. 
Tablo 5. Bölüm İle Siberkondri Ortalaması Arasındaki Bağımsız Gruplarda Tek Yönlü Varyans Testi

\begin{tabular}{|c|c|c|c|c|c|c|c|}
\hline Bölüm & & $\mathbf{n}$ & Ort. & Sd & $\mathbf{F}$ & $\mathrm{p}$ & Post-Hoc(Games-Howel) \\
\hline $\begin{array}{c}\text { Siberkondri } \\
\text { Ortalaması }\end{array}$ & $\begin{array}{l}\text { 1)Çocuk Gelişimi } \\
\text { 2)Sağlık Yönetimi } \\
\text { 3)Beslenme Diyetetik } \\
\text { 4)Sosyal Hizmet } \\
\text { 5) Hemşirelik }\end{array}$ & $\begin{array}{l}74 \\
115 \\
65 \\
99 \\
98\end{array}$ & $\begin{array}{l}2,8152 \\
2,4050 \\
2,6423 \\
2,5426 \\
2,4865\end{array}$ & $\begin{array}{l}, 57101 \\
, 60720 \\
, 67162 \\
, 57433 \\
, 60790\end{array}$ & 6,859 & 0,000 & $1>2,4,5$ \\
\hline $\begin{array}{l}\text { İşlevsel } \\
\text { Olmayan } \\
\text { İnternet } \\
\text { Kullanımı }\end{array}$ & $\begin{array}{l}\text { 1)Çocuk Gelişimi } \\
\text { 2)Sağlık Yönetimi } \\
\text { 3)Beslenme Diyetetik } \\
\text { 4) Sosyal Hizmet } \\
\text { 5) Hemşirelik }\end{array}$ & $\begin{array}{l}74 \\
115 \\
65 \\
99 \\
98\end{array}$ & $\begin{array}{l}3,0901 \\
2,7333 \\
2,9692 \\
3,0135 \\
2,7613\end{array}$ & $\begin{array}{l}, 76326 \\
, 74953 \\
, 80358 \\
76141 \\
, 78080\end{array}$ & 4,107 & 0,003 & $1>2,5$ \\
\hline $\begin{array}{l}\text { Doktor- } \\
\text { Hasta } \\
\text { Etkileşimi }\end{array}$ & $\begin{array}{l}\text { 1)Çocuk Gelişimi } \\
\text { 2)Sağlık Yönetimi } \\
\text { 3)Beslenme Diyetetik } \\
\text { 4) Sosyal Hizmet } \\
\text { 5) Hemşirelik }\end{array}$ & $\begin{array}{l}74 \\
115 \\
65 \\
99 \\
98 \\
\end{array}$ & $\begin{array}{l}2,8122 \\
2,4035 \\
2,5200 \\
2,3859 \\
2,4919 \\
\end{array}$ & $\begin{array}{l}\text { 67706 } \\
\text {,88376 } \\
\text {,89986 } \\
, 81978 \\
, 90004 \\
\end{array}$ & 4,299 & 0,002 & $1>2,5$ \\
\hline $\begin{array}{l}\text { Kompülsiyon } \\
\text { /Hipokondri }\end{array}$ & $\begin{array}{l}\text { 1)Çocuk Gelişimi } \\
\text { 2)Sağllk Yönetimi } \\
\text { 3)Beslenme Diyetetik } \\
\text { 4) Sosyal Hizmet } \\
\text { 5) Hemşirelik }\end{array}$ & $\begin{array}{l}74 \\
115 \\
65 \\
99 \\
98 \\
\end{array}$ & $\begin{array}{l}2,6173 \\
1,7447 \\
2,3179 \\
2,0303 \\
1,9887 \\
\end{array}$ & $\begin{array}{l}, 79777 \\
\text { 65350 } \\
\text {,84457 } \\
\text {,78223 } \\
, 71478 \\
\end{array}$ & 9,853 & 0,000 & $1>2,4,5$ \\
\hline $\begin{array}{l}\text { Kaygıyı } \\
\text { Azaltan } \\
\text { Faktörler }\end{array}$ & $\begin{array}{l}\text { 1)Çocuk Gelişimi } \\
\text { 2)Sağlık Yönetimi } \\
\text { 3)Beslenme Diyetetik } \\
\text { 4) Sosyal Hizmet } \\
\text { 5) Hemşirelik }\end{array}$ & $\begin{array}{l}74 \\
115 \\
65 \\
99 \\
98 \\
\end{array}$ & $\begin{array}{l}2,6811 \\
2,7096 \\
2,7262 \\
2,7152 \\
2,7388 \\
\end{array}$ & $\begin{array}{l}\text {,87768 } \\
, 74185 \\
, 75463 \\
\text {,67678 } \\
, 64114 \\
\end{array}$ & 0,071 & 0,991 & \\
\hline $\begin{array}{l}\text { Kaygıyı } \\
\text { Arttıran } \\
\text { Faktörler }\end{array}$ & $\begin{array}{l}\text { 1)Çocuk Gelişimi } \\
\text { 2)Sağlık Yönetimi } \\
\text { 3)Beslenme Diyetetik } \\
\text { 4) Sosyal Hizmet } \\
\text { 5) Hemşirelik }\end{array}$ & $\begin{array}{l}74 \\
115 \\
65 \\
99 \\
98\end{array}$ & $\begin{array}{l}2,5428 \\
2,4841 \\
2,6718 \\
2,5707 \\
2,8044\end{array}$ & $\begin{array}{l}, 83039 \\
, 85896 \\
, 79820 \\
, 83946 \\
, 74383\end{array}$ & 2,344 & 0,054 & \\
\hline
\end{tabular}

Tablo 6' da görüldüğü üzere araştırmaya dâhil olan kişilerin yıllık doktora başvuru sayıları ile siberkondri ölçeği alt boyut ortalamaları arasında tek yönlü varyans testi yapılmıştır. Yıllık doktora başvuru süresi ile işlevsel olmayan internet kullanımı arasında anlamlı bir fark bulunmuştur $(p<0,05)$. Siberkondri ileyıllık doktora başvuru ortalamaları arasında yapılan Post-Hoc (Games-Howell) testine göre: Yıllık doktora 6-10 ( $\bar{x}=3,00)$ arasında başvuranların siberkondri düzeyleri, yıllık 1-5 ( $\overline{\mathrm{x}}=2,91)$ arasında başvuranlara göre daha yüksek olduğu sonucuna ulaşılmıştır. 
Tablo 6. Doktora Başvuru Sayısı İle Siberkondri Ortalaması Arasında Bağımsız Gruplarda Tek Yönlï Varyans Testi

\begin{tabular}{llllllll}
\hline Doktora Başvuru Sayısı & & $\mathbf{n}$ & Ort. & Sd & F & p & Post-Hoc \\
\hline Siberkondri & $1-5$ & 147 & 2,570 & 0,55975 & & & \\
Ortalaması & $6-10$ & 215 & 2,5809 & 0,64673 & 0,162 & 0,851 & \\
& $11-15$ & 89 & 2,5385 & 0,64320 & & & \\
\hline İslevsel & $1-5$ & 147 & 2,9109 &, 77874 & & & \\
Olmayan & $6-10$ & 215 & 3,0093 &, 77618 & 4,719 & 0,009 & $2>1$ \\
İnternet Kullanımı & $11-15$ & 89 & 2,9288 &, 87973 & & & \\
\hline Doktor- & $1-5$ & 147 & 2,5592 &, 83713 & & & \\
Hasta & $6-10$ & 215 & 2,5209 &, 86245 & 0,447 & 0,640 & \\
Etkileşimi & $11-15$ & 89 & 2,4517 &, 82546 & & & \\
\hline Kaygiyı & $1-5$ & 147 & 2,6327 &, 78294 & & & \\
Arttıran & $6-10$ & 215 & 2,5853 &, 84737 & 0,177 & 0,838 & \\
Faktörler & $11-15$ & 89 & 2,6292 &, 83134 & & & \\
\hline Kaygiyı & $1-5$ & 147 & 2,8082 &, 71227 & & & \\
Azaltan & $6-10$ & 215 & 2,6633 &, 73172 & 1,813 & 0,164 & \\
Faktörler & $11-15$ & 89 & 2,6854 &, 75190 & & & \\
\hline Kompülsiyon & $1-5$ & 147 & 2,1735 &, 81810 & & & \\
,/Hipokondri & $6-10$ & 215 & 2,1295 &, 82671 & 1,182 & 0,308 & \\
& $11-15$ & 89 & 2,0075 &, 77480 & & & \\
\hline
\end{tabular}

Tablo 7. Günlük Internette Geçirilen Süre, Gelir ve Algılanan Genel Sağhk Durumu İle Siberkondri Arasındaki İlişkiye Ait Korelâsyon Analizi

\begin{tabular}{llllll}
\hline & & $\mathbf{1}$ & $\mathbf{2}$ & $\mathbf{3}$ & $\mathbf{4}$ \\
\hline İnternette Geçirilen Süre & & 1 & & & \\
\hline Siberkondri & $\mathrm{r}$ &, $098^{*}$ & 1 & & \\
& $\mathrm{p}$ & 0,037 & & & \\
\hline Gelir & $\mathrm{r}$ & &, $133^{* *}$ & 1 & \\
& $\mathrm{p}$ & &, 005 & & \\
\hline Algilanan Genel Sağlık Durumu & $\mathrm{r}$ & &,$- 173^{* *}$ & & 1 \\
& $\mathrm{p}$ & &, 000 & & \\
\hline$N=451^{*}<<001^{* *} p<0.05$ & & & &
\end{tabular}

$N=451{ }^{*} p<0.001,{ }^{* *} p<0.05$

Tablo 8'de görüldüğü üzere günlük internette geçirilen süre, gelir ve alg-lanan genel sağlık durumu ile siberkondri arasındaki ilişkiye ait korelasyon analizi yapılmıştır. Analiz sonucuna göre günlük internette geçirilen süre ile siberkondri düzeyi arasında zayıf, pozitif ve istatistiksel bakımdan anlamlı bir ilişkinin olduğu görülmektedir (r: 0,098 ve p<0,05). Algılanan genel sağlık durumu ile siberkondri düzeyi arasında arasında zayıf, negatif ve istatistiksel bakımdan anlamlı bir ilişkinin olduğu görülmektedir ( $r:-, 173$ ve $p<0,001)$. Ayrıca yapılan korelasyon analizi sonucuna göre gelir ile siberkondri düzeyi 
arasında zayıf, pozitif yönde anlamlı bir ilişki olduğu görülmüştür. (r: 0,133 ve $\mathrm{p}<0,001)$

\section{Tartışma ve Sonuç}

Çalışmada bireylerin siberkondri düzeyleri ve ilişkili faktörlerin incelenmesi amaçlanmaktadır. Araştırma sonucuna göre kadınların siberkondri düzeylerinin daha yüksek olduğu sonucuna varılmıştır. Çalışmamızla paralel olarak Uzun (2016), Barke ve ark. (2016), çalışmasında da kadınların siberkondri puanları daha yüksek bulunmuştur.White ve Horvitz (2009)'ın çalışmasında kadınların daha fazla internetten sağlık bilgisi aradığını ve bu işlem sonrasında erkeklere göre daha fazla anksiyöz hissettikleri sonucuna ulaşılmıştır. 2015 TUIK verilerine göre kadınlar erkeklere göre daha fazla çevrimiçi sağlık araması yapmaktadır (TUIK, 2015). Benzer şekilde Rice (2016)'ın çalışmasında da kadınlar daha fazla çevrimiçi sağlık araması yapmaktadır. Kadınların çevrimiçi sağlık arama oranlarının erkeklere nazara yüksek olmasında; kadınların sadece kendileri için değil ailesi ve arkadaşları içinde sağlık bilgisi araması yaptığı etkili olabilir (Uzun, 2016, s.70). Gray ve ark (2002) çalışmasında kadınların, kendileri haricinde akrabaları için de çevrimiçi sağlık bilgisi aradığı sonucuna varılmıştır.

Çalışma sonucunda sürekli ilaç kullanan bireylerin siberkondri düzeyleri kullanmayanlara göre daha yüksek çıkmıştır. Ayrıca sürekli ilaç kullanan ve kronik hastalığa sahip bireylerin işlevsel olmayan internet kullanımı ve doktor hasta etkileşimlerinin daha yüksek olduğu sonucuna varılmıştı. Bununla birlikte işlevsel olmayan internet kullanımının daha fazla doktora başvuru ile sonuçlanacağı görülmüştür.Illhan ve ark.(2006)'nın yaptığı çalışmada kronik hastalığı olan bireylerin ve kadınların sağlık kuruluşlarına daha çok başvurduğu görülmüştür.Rice (2006), Yılmaz (2013), Baker ve ark. (2003)'nın çalışmalarında da kendisinde veya ailesinde kronik hastalık veya spesifik bir hastalığı olan bireylerin çevrimiçi sağlık bilgisi arama davranışının daha yüksek olduğu sonucuna varılmıştıri. Ayrıca Fergus (2014)'un çalışmasında siberkondrinin gereksiz ilaç kullanımını arttığı dolayısı ile sağlık harcamalarını arttırdığı sonucuna ulaşılmıştır. Siberkondriyak bireylerin gereksiz ilaç kullanımından dolayısı ilaç kullanım oranı yüksek olabilir veya düzenli kullanması gereken ilacı internette yer alan bilgiler ışığında bırakması sonucu ilaç kullanımları düşük de olabilir. Her iki durumda da harcamaları arttıracağı, 
sağlık yönetimini geciktirebileceği, şikâyetleri sonlandırmayacağı ve sonucunda daha fazla gereksiz sağlık hizmeti alımına neden olabileceği beklenmektedir (Sibel, 2013, s.115).

Çalışma sonucuna göre internette günlük geçirilen süre ile siberkondri düzeyi arasında güçlü, pozitif ve istatistiksel bakımdan anlamlı bir ilişki saptanmıştır. Başoğlu (2018)'nun yaptığı çalışmada bireylerin sosyal medya haricinde internette geçirdikleri zaman ile siberkondri düzeyi arasında pozitif yönlü bir ilişki saptanmıştır. Karmpaul (2014)'un üniversite öğrencileri üze-

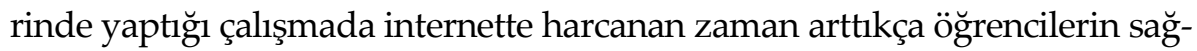
lık anksiyetelerinin arttığı sonucuna varılmıştır. Rice'ın 2006 yılında yaptığı çalışmada ise bireylerin internette geçirdikleri zaman arttıkça daha fazla sağlık bilgisi arama davranışına yöneldikleri sonucuna ulaşılmıştır. Çalışma sonucunda gelir ile siberkondri düzeyi arasında zayıf, pozitif ve istatistiksel bakımdan anlamlı bir ilişki saptanmıştır. Murray ve ark (2003)'ın çalışmasında yüksek sosyoekonomik şartlara sahip bireylerin daha fazla çevrimiçi sağlık bilgisi aradığı görülmüştür. Çalışmamızla paralel olarak Sertbaş (2007), Çucu (2001) çalışmalarında gelir durumu yüksek bireylerin düşük sağlık kaygısına sahip oldukların tespit etmişlerdir. Çalışma sonucunda bireylerin algılanan sağlık durumları iyiye gittikçe siberkondri düzeyinin düşeceği tespit edilmiştir. İnternette yer alan filtresiz bilgilerin aşırılı̆̆ı göz önüne alındığında bu bilgilerin bireylerin sağlık kaygılarının arttırabileceği ve sonucunda bir uzmana danışma ihtiyacı hissetmeleri olasıdır. Çalışma sonucunda çocuk gelişimi bölümünde öğrenim gören öğrencilerinin siberkondri ve hipokondri düzeyleri, işlevsel olmayan internet kullanımları ve doctor- hasta etkileşimlerinin hemşirelik, sosyal hizmet ve sağllk yönetimi bölümlerinde öğrenim gören öğrencilerden daha yüksek olduğu görülmüştür. Bu durum gerek hastane uygulamları gerekse de aldıkları dersler göz önüne alındığında hemşirelik, beslenme ve diyetetik, sağlık yönetimi bölümleri öğrencilerinin sağlık bilgi kaynaklarına ve hizmetlerine çocuk gelişimi öğrencilerine göre daha kolay erişebilmeleri sebebiyle olabilir. 
EXTENDED ABSTRACT

\title{
Study Of Cybercondria Levels And Related Factors Of Faculty Of Health Sciences Students
}

*

\author{
Handan Ertaş - Ramazan Kıraç_- Seda Nur Ünal \\ Selçuk University, Kahramanmaraş University
}

While health anxiety is a misunderstanding about their health by misinterpreting any sensation that develops in the body of individuals; cyberchondria is defined as a serious increase in individuals' health anxiety as a result of online searches on health (Asmundson \& Taylor, 2005, p.3; Muse et all., 2012, p. 190). Starcevic and Berle (2013) define cyberchondria as long-term and intensive internet use to reduce health-related anxiety. High health anxiety is not only limited to the distress of the patient and his environment, but also brings high medical care use (Barsky, Ettner, Horsky \& Bates, 2001).

Siberchoriacians easily access unfiltered health information through search engines. Studies have concluded that the quality and accuracy of the information contained in health-related sites are questionable (Kunst, Groot, Latthe, Khan, 2002; Rajani, Mukherjee, Chambers, Murmurs, 2007). Therefore, using the internet to obtain health related information may increase the risk of individuals being exposed to conflicting, incorrect or outdated information. In their study, White and Horvitz (2009), search engines are directed to pages that will cause more serious and negative effects to searchers according to various symptoms, and these serious results increase the anxiety of individuals and conduct in-depth research. In the same study, it was concluded that such searches negatively affect the daily life of individuals. When the studies conducted are examined, it is concluded that there is a positive relationship between cyberchondria and health anxiety, people with high health anxiety scores spend more time on the internet and these people have more anxiety and distress after searching the internet (Norr, Allan, Boffa, Raines, Schmidt, 2015; Barke, Bleichhardt, Rief, Doering, 2016; Norr, Albanese, Oglesby, Allan, Schmidt, 2015; Baumgartner and Hartmann, 2011). 
Some studies focus on the relationship between cyberchondria and health services. Fergus (2014) stated that cyberchondria, which causes anxiety, will also increase healthcare use. In the study of Fox (2015), 46\% of individuals seeking online health information feel the need to consult their healthcare staff in line with the information they have obtained. Berezovska et al. (2010), it was concluded that $30 \%$ of people who search for healthcare online use healthcare. Ravdin and Guide (2008) and Keller, Paradala, Petty (2008) emphasize that cyberchondria can cause negativities in doctor-patient communication. This will cause the person to spend extra health (eg doctor doctor visit). In this context, considering both the health problems it causes and the costs it may cause, cyberchondria should be better understood. In addition, it is important to identify strategies to understand this situation and to minimize its negative effects. Health managers, psychologists, public health and information technology specialists should work in cooperation in determining these strategies. In this context, it is very important to know cyberchondria for students who will start their profession professionally when they graduate. In this study, it is aimed to investigate the cyberchondria levels and related factors of the Faculty of Health Sciences students. Since the studies on the subject are limited, it is thought that the study will support the literature.

In recent years with the development of technolog, individuals access information mostly from digital media. Since it is faster to access information from digital environments, people prefer this way to access information about health. However, since there is a lot of information pollution in these environments, individuals have difficulty in reaching the correct information or the information they access increases the level of anxiety in the individual. The aim of this study is to investigate the cyberchondria levels and related factors of the students of the Faculty of Health Sciences. The sample of the study consists of 450 students studying at the Faculty of Health Sciences of Selçuk University. In the study Batıgun et.al. (2018) was used by the 28-item Cyberchondria Scale. $54.3 \%$ of the participants were female, $25.5 \%$ were in Health Management and $14.4 \%$ were in Nutrition and Dietetics. $49.2 \%$ of the students spend 4-6 hours, 19\% 7-9 hours on the internet and $67.7 \%$ do not trust the information on the internet. Looking at the number of doctorate applications in the last year, $47.7 \%$ of the students stated that they have applied for doctorate 6-10 times, and $19.7 \%$ stated that they have applied for doctorate 
11-15 times. According to the results of the study, it was concluded that cyberchondria levels of women and students with continuous drug use were higher. As a result of the study, it was found that as the perceived health status of individuals improved, the cyberchondria level would decrease.

\section{Kaynakça / References}

Aiken, M., Kirwan, G., Berry, M., ve O'Boyle, C.A.(2012) The age of cyberchondria. Royal College Of Surgeons In Ireland Student Medical Journal, 5, 71-74.

Altunışık, R., Coşkun, R., Bayraktaroğlu, S., ve Yıldırım, E. (2007). Sosyal bilimlerde araştırma yöntemleri: SPSS uygulamalı. Sakarya Yayıncılık.

Baker, L., Wagner, T. H., Singer, S., ve Bundorf, M. K. (2003). Use of the internet and e-mail for health care information: Results from a national survey. Jama, 289(18), 2400-2406.

Barke, A., Bleichhardt, G., Rief, W., ve Doering, B. K. (2016). The cyberchondria severity scale (CSS): German validation and development of a short form. International Journal Of Behavioral Medicine, 23(5), 595-605.

Barsky, A. J., Ettner, S. L., Horsky, J., ve Bates, D. W. (2001). Resource Utilization Of Patients With Hypochondriacal Health Anxiety And Somatization. Medical Care, 705-715.

Baumgartner, S. E., ve Hartmann, T. (2011). The role of health anxiety in online health information search. Cyberpsychology, Behavior, And Social Networking, 14(10), 613-618.

Benigeri, M., ve Pluye, P. (2003). Shortcomings of health information on the internet. Health Promotion International, 18(4), 381-386.

Berezovska, I., ve Matsyuk, O. (2010). Evolving facets of cyberchondria: Primum non nocere" first, do no harm. In 7th International Conference Hands-On Science (Hsci2010), Crete: Greece.

Çucu, N.Ö. (2001). Adölesan gebelerin kaygı düzeylerinin ve prenatal risk faktörlerinin incelenmesi. Yayımlanmamış Yüksek Lisans Tezi, Ege Üniversitesi, İzmir, Türkiye.

Durak-Batigun, A., Gör, N., Komurcu, B., ve Senkal-Erturk, I.(2018). Cyberchondria scale(CS): Development, validity and reliability study. Dusunen Adam The Journal Of Psychiatry Andneurological Sciences,31,148-162 
Fergus, T. A. (2014). The cyberchondria severity scale (CSS): An examination of structure and relations with health anxiety in a community sample. Journal Of Anxiety Disorders, 28(6), 504-510.

Fox, S. ve Duggan, M.(2013). Online health search 2013. Pew Internet \& American Life Project. 14 Ağustos 2019 tarihinde Http://Www.Pewinternet.Org/Files/Oldmedia/Files/Reports/PIP Healthonline.Pdf adresinden erişilmiştir.

Gray, N. J., Klein, J. D., Cantrill, J. A., ve Noyce, P. R. (2002). Adolescents' perceptions of the internet as a health information source. International Journal Of Pharmacy Practice, 10(S1), R53-R53.

Huberty, J., Dinkel, D., Beets, M. W., ve Coleman, J. (2013). Describing the use of the internet for health, physical activity, and nutrition information in pregnant women. Maternal And Child Health Journal, 17(8), 1363-1372.

Kaplan, S., Bahar, A., ve Sertbaş, G. (2007). Gebelerde doğum öncesi ve doğum sonrasi dönemlerde durumluk kaygi düzeylerinin incelenmesi. Anadolu Hemşirelik Ve Sağlık Bilimleri Dergisi, 10(1), 113-121.

Keller, G. L., Padala, P. R., ve Petty, F. (2008). Clinical pearls to manage cyberchondriacs. Primary Care Companion To The Journal Of Clinical Psychiatry, 10(1), 75 .

Kunst, H., Groot, D., Latthe, P. M., Latthe, M., ve Khan, K. S. (2002). Accuracy of information on apparently credible websites: Survey of five common health topics. Bmj, 324(7337), 581-582.

Küçükoğlu, S., Polat, S., ve Güdek, E. (2013). Annelerin evde ilaçları saklama koşullarıyla ilgili bilgi ve uygulamalarının belirlenmesi. Anadolu Hemşirelik Ve Sağlık Bilimleri Dergisi, 16(4), 212-218.

Lemire, M., Sicotte, C., ve Paré, G. (2008). Internet use and the logics of personal empowerment in health. Health Policy, 88(1), 130-140.

Lhan, M., Tüzün, H., Aycan, S., Aksakal, F. N., ve Özkan, S. (2006). Birinci basamak sağlık kuruluşuna başvuranların sağlık hizmeti kullanma özellikleri ve bazı sosyoekonomik belirteçlerle değişimi: Sağlık reformu öncesi son saptamalar. Toplum Hekimliğgi Bülteni, 25(3), 33-41

Mathes, B. M. , Norr, A. M. , Allan, N. P., Albanese, B. J. ve Schmidt, N. B. (2018). Cyberchondria: Overlap with health anxiety and unique relations with impairment, quality of life, and service utilization. Psychiatry Research, 261, 204-211. 
Mcelroy, E. ve Shevlin, M. (2014). The development and initial validation of the cyberchondria severity scale (CSS). Journal Of Anxiety Disorders, 28(2), 259-265.

Muse, K. , Mcmanus, F. , Leung, C. , Meghreblian, B. , ve Williams, J. M. G. (2012). Cyberchondriasis: Fact or fiction? a preliminary examination of the relationship between health anxiety and searching for health information on the internet. Journal Of Anxiety Disorders, 26(1), 189-196.

Norr, A. M. , Allan, N. P. , Boffa, J. W. , Raines, A. M., ve Schmidt, N. B. (2015). Validation of the cyberchondria severity scale (CSS): Replication and extension with bifactor modeling. Journal Of Anxiety Disorders, 31, 58-64

Rains, S. A. (2007). Perceptions of traditional information sources and use of the world wide web to seek health information: Findings from the health information national trends survey. Journal Of Health Communication, 12(7), 667-680.

Rajani, R., Mukherjee, D., ve Chambers, J. (2007). Murmurs: How reliable is information on the internet?.International Journal Of Cardiology, 119(1), 112-113.

Ravdin, L. D. (2008). Guide for clinicians in the age of cyberchondria-understanding somatization in the practice of clinical neuropsychology.Journal of The International Neuropsychological Society, 14(5), 912-913.

Rice, R. E. (2006). Influences, usage, and outcomes of internet health information searching: Multivariate results from the pew surveys. International Journal Of Medical Informatics, 75(1), 8-28.

Singh, K., ve Brown, R. J. (2014). Health-related internet habits and health anxiety in university students. Anxiety, Stress, \& Coping, 27(5), 542-554.

Starcevic, V. ve Berle, D. (2013). Cyberchondria: Towards a better understanding of excessive health-related internet use. Expert Review Of Neurotherapeutics, 13(2), 205-213.

TÜIKK Hane Halkı Bilişim Teknolojileri Kullanım Araştırması. (2015) Son üç ay içinde internet kullanan bireylerin kişisel amaçla internet üzerinde yürüttüğü faaliyetler. 15 Ağustos 2019 tarihinde www.Tuik.Gov.Tr/Hbgetir.Do?İd=18660\&Tb İd=15 adresinden erişilmiştir.

TÜIK.(2015). Hane halkı bilişim teknolojileri kullanım araştırması. 15 Ağustos 2019 Http://Www.Tuik.Gov.Tr/Prehaberbultenleri.Do?İd=18660 tarihinde adresinden erişilmiştir. 
Uzun, S. U. (2016). Pamukkale Üniversitesi çalışanlarında siberkondri düzeyi ve etkileyen etmenler. Yayımlanmamış Yüksek Lisans Tezi, Pamukkale Üniversitesi, Denizli, Türkiye.

White, R. W. ve Horvitz, E. (2009). Cyberchondria: Studies of the escalation of medical concerns in web search. ACM Transactions On Information Systems (TOIS), 27(4), 23.

Yazıcıoğlu, Y. ve Erdoğan, S. (2004). SPSS uygulamalı bilimsel araştırma yöntemleri. Ankara: Detay Yayıncilik.

Yılmaz, E. (2014). Türkiye'de hastaların internette tıbbi enformasyon arama davranışlarının doktor-hasta iletişimine etkileri. Galatasaray Üniversitesi Iletişim Dergisi, 93-108.

\section{Kaynakça Bilgisi / Citation Information}

Ertaş, H., Kıraç, R. ve Ünal. (2020). Sağlık bilimleri fakültesi öğrencilerinin siberkondri düzeyleri ve ilişkili faktörlerin incelenmesi. OPUSUluslararası Toplum Araştırmaları Dergisi, 15(23), 1746-1764. DOI: 10.26466-/opus.616396 